\title{
Knowledge, attitude and self-efficacy program intended to improve public health professionals' ability to identify and manage perinatal depressive symptoms: a quasi-experimental study
}

Nitikorn Phoosuwan ${ }^{1,2^{*}}$ (D) and Pranee C. Lundberg ${ }^{1}$

\begin{abstract}
Background: During the perinatal period women lack screening and treatments for perinatal depressive symptoms, while public health professionals (PHPs) in primary care centres (PCCs) need training for identification and management of such symptoms. This quasi-experimental study was aimed at evaluating knowledge, attitudes and self-efficacy among PHPs after participating in a Knowledge, Attitude, and Self-efficacy (KAS) program for identification and management of perinatal depressive symptoms.

Method: The KAS-program, carried through in Sakonnakhon in north-eastern Thailand, comprised one day of theory and a four-week period of field practice. Thirty-three PHPs from PCCs participated in the program. Twentythree of them participated in focus group discussions (FGDs). Chi-square for trend, paired-sample T-tests and content analysis were used.

Results: Knowledge, attitude and self-efficacy scores increased after the PHPs had fully participated in the KASprogram. Four categories emerged from the FGDs: increased understanding and knowledge, being aware and having a positive attitude, having confidence and ability to work, and need of regular training and feedback.

Conclusion: The KAS-program may contribute to giving PHPs in PCCs the knowledge, positive attitude and selfefficacy they need to identify and manage perinatal depressive symptoms. Implementation of the KAS-program to other healthcare professionals such as nurses/midwives is great of interest.
\end{abstract}

Keywords: Attitude, Healthcare professionals, Knowledge, Public health professionals, Self-efficacy, Thailand, Training program

\footnotetext{
* Correspondence: nitikorn.phoosuwan@pubcare.uu.se;

doctor.nitikorn@gmail.com

${ }^{1}$ Department of Public Health and Caring Sciences, Faculty of Medicine, Uppsala University, BMC, Husargatan 3, Box 564, 75122 Uppsala, Sweden 2Department of Community Health, Faculty of Public Health, Kasetsart University Chalermphrakiat Sakonnakhon Province Campus, Chiang Khruea sub-district, Muang Sakon Nakhon, Sakon Nakhon Province, Thailand
}

C The Author(s). 2021 Open Access This article is licensed under a Creative Commons Attribution 4.0 International License, which permits use, sharing, adaptation, distribution and reproduction in any medium or format, as long as you give appropriate credit to the original author(s) and the source, provide a link to the Creative Commons licence, and indicate if changes were made. The images or other third party material in this article are included in the article's Creative Commons licence, unless indicated otherwise in a credit line to the material. If material is not included in the article's Creative Commons licence and your intended use is not permitted by statutory regulation or exceeds the permitted use, you will need to obtain permission directly from the copyright holder. To view a copy of this licence, visit http://creativecommons.org/licenses/by/4.0/. The Creative Commons Public Domain Dedication waiver (http://creativecommons.org/publicdomain/zero/1.0/) applies to the data made available in this article, unless otherwise stated in a credit line to the data. 


\section{Background}

Depression is one of the most common mental disorders occurring in women during the perinatal period $[1,2]$. Worldwide, nearly $40 \%$ of women experience psychological distress due to depressive symptoms during the perinatal period [3]. If women with perinatal depressive symptoms are under-screened and untreated they may suffer from negative short-term as well as long-term effects [4], such as reduced mother-to-child attachment and reduced self-efficacy [5].

There are a large number of empirically-supported interventions for treating perinatal depression in at-risk women in primary care and obstetrics/gynecology practices. There are also interventions such as counseling intervention, psychosocial or psychological intervention and interpersonal psychotherapy from other clinical settings [6-8]. Training is important also for mental health practitioners. Training for them, aimed at improving their knowledge and attitudes, may be a strong factor for better recovery $[9,10]$. As improved knowledge and attitudes may not last over time, their training may need to take place steadily or repeatedly [10-13]. Nonetheless, there is lack of screening, and often women with depressive symptoms have not been well-managed during the perinatal period $[4,8]$. Improving women's mental health is a part of the third of the sustainable development goals, viz. reduction of premature mortality [14], and women need improved identification and management of depressive symptoms during the perinatal period [7, 8, 15].

Healthcare professionals (HCPs) are responsible for management of depressive symptoms in primary care centers (PCCs) and antenatal care (ANC) clinics [15, 16]. However, they do not always accurately identify depressive symptoms in pregnant women [4]. In part, this is due to their lack of familiarity with standardized depression screening tools, such as the Edinburgh Postnatal Depression Scale (EPDS) [17]. In addition, HCPs may lack knowledge about the process of referral and diagnostic assessment $[3,10]$.

The EPDS is a recommended screening tool that is applicable in PCCs [18]. Public health professionals (PHPs) in PCCs are important persons for effective provision of mental health care $[19,20]$. Therefore, improving the ability of PHPs in PCCs to identify perinatal depressive symptoms among women by use of the EPDS is important [17].

In Thailand, depression screening has been launched in PCCs, and women in the perinatal period are classified in a high-risk group for depression [21]. Each of the 76 provinces in Thailand has several PCCs, and every PCC is responsible for a population of 3000-8000. About four HCPs work in each PCC; two PHPs work with disease prevention and health promotion, and one nurse/midwife and one public health assistant work with common illnesses and rehabilitation of patients [22]. PHPs should work toward identification and management of perinatal depressive symptoms among women during the perinatal period [21]. However, the PHPs need capacity-building programs devoted to knowledge of and attitude towards management of perinatal depressive symptoms among women who receive ANC in their PCCs [21, 23, 24]. As tools for screening such symptoms are essential for PHPs, a program focusing on identification of perinatal depressive symptoms could improve their self-efficacy [25].

Research has demonstrated a link between attitudes and behavior, with attitudes viewed as antecedents of behavior [26]. In order to change a behavior among HCPs, understanding of their attitudes toward that behavior and training are necessary [27]. Currently, very little research has been focused on attitudes and behavior among HCPs, such as those who work with identification and management of perinatal depressive symptoms at primary care setting $[3,26]$.

The knowledge of HCPs is related to their attitude, which in turn is related to their self-efficacy. The selfefficacy of HCPs is a key factor for improving women's mental health because women may trust and follow guidance from those who have high level of self-efficacy $[24,28]$. The knowledge of HCPs may be low if they have insufficient experience of a specific task or lack of training $[9,23]$. Their attitude can be improved through a training program $[9,25,29]$.

According to the theory of self-efficacy [30], this concept focuses on efficacy expectations, comprising four sources of information: performance accomplishment, vicarious experience, verbal persuasion, and physiological states. Knowledge and attitude may contribute to performance accomplishment; vicarious experience comes when a person succeeds in a specific task, supervision enhances verbal persuasion, and physiological states come from a non-verbal action from an expert. If HCPs in PCCs have sufficient knowledge, positive attitude and high self-efficacy to identify and manage perinatal depressive symptoms, women may have better chance to access healthcare services and to be treated [4, 18]. A training program targeting PHPs in PCCs may be of great interest for improvement of PHPs' knowledge, attitude and selfefficacy in order to make them identify and manage perinatal depressive symptoms effectively [10, 17, 19]. To improve knowledge, attitude and self-efficacy among PHPs for identification and management of perinatal depressive symptoms, a knowledge, attitude and self-efficacy program (KAS-program) was developed as a training program for this study. 


\section{Methods}

\section{Aim}

The aim of this study was to evaluate knowledge, attitude and self-efficacy among PHPs in PCCs in northeastern Thailand after they had participated in a KAS-program for identification and management of perinatal depressive symptoms.

\section{Study setting and design}

Data were collected in Sakonnakhon, a northeastern province of Thailand. Sakonnakhon has about 300 PHPs, with a bachelor's degree in public health, working at 168 PCCs. The number of childbirths annually is high [31]. This quasi-experimental study utilized mixed methods approach [32, 33] in which quantitative method was used to demonstrate the changes of knowledge, attitude and self-efficacy scores of PHPs for identification and management of perinatal depressive symptoms during the KAS-program, while qualitative method provided a rich source of information to understand the process during and after implementation of the KAS-program.

\section{Knowledge, attitude, and self-efficacy (KAS) program for identification and management of perinatal depressive symptoms}

The KAS-program was developed by the authors (NP and PCL) on the basis of the theory of self-efficacy [30].
It contained two parts: (1) a full day $(8 \mathrm{~h})$ of theory and (2) a four-week period of field practice. See Fig. 1.

The day of theory included interactive lectures provided by three experts in the fields of public health, behavioral science and psychiatric nursing. It focused on knowledge of, attitude towards and self-efficacy for identification and management of perinatal depressive symptoms. Two guidelines were used. One from the World Health Organization [34], translated into Thai language by NP, dealt with psychosocial management. Another, constructed by the authors, was devoted to identification and management of perinatal depressive symptoms. A questionnaire used among north-eastern Thai women, was also included. It comprised four parts: (1) the Thai EPDS part for screening women during the perinatal period [1, 5, 35, 36], (2) the psychological well-being question part [37], (3) the self-esteem question part [38] and (4) the sense of coherence question part [1,39]. The participants were given the guidelines and a copy of the questionnaire for practice.

The four-week period of field practice started immediately after the day of theory. During 4 weeks, the participants were asked to practice with two women or more (one pregnant woman and one woman after childbirth) visiting the ANC clinic at their PCC. For this practice they used the guidelines and the questionnaire presented in the day of theory. In order to assist the participants,

\begin{tabular}{|c|c|}
\hline \multicolumn{2}{|c|}{ KAS-program for identification and management of perinatal depressive symptoms } \\
\hline & \\
\hline A day of theory & A four-week period of practice \\
\hline $\begin{array}{l}\text { Performance accomplishment } \\
\text { • Knowledge relating to risk factors associated with } \\
\text { perinatal depressive symptoms among women } \\
\text { • Outcomes of identification and management of } \\
\text { perinatal depressive symptoms } \\
\text { Vicarious experience } \\
\text { - Shared experience in how to manage perinatal } \\
\text { depressive symptoms } \\
\text { Verbal persuasion } \\
\text {-Attitude towards identification and management } \\
\text { of perinatal depressive symptoms } \\
\text { Physiological states } \\
\bullet \text { Psychosocial management manual and guidelines } \\
\text { for identification and management of perinatal } \\
\text { depressive symptoms } \\
\bullet \text { A questionnaire to identify perinatal depressive } \\
\text { symptoms and its associated factors }\end{array}$ & $\begin{array}{l}\text { Performance accomplishment } \\
\bullet \text { Group discussions regarding understanding about } \\
\text { risk factors associated with perinatal depressive } \\
\text { symptoms among women and outcomes of } \\
\text { identification and management of the symptoms } \\
\text { Vicarious experience } \\
\text { •Identification and management for perinatal } \\
\text { depressive symptoms among women in the community } \\
\text { Verbal persuasion } \\
\text { • Supervision of the participants by phone and } \\
\text { mobile applications } \\
\text { Physiological states } \\
\bullet \text { Supervision of the participants by face-to-face } \\
\text { visits }\end{array}$ \\
\hline
\end{tabular}

Fig. 1 Contents of the Knowledge, Attitude and Self-Efficacy Program (KAS-program) in relation to the four main components of the Bandura's self-efficacy theory [30] 
NP supervised them by use of mobile applications (Line and Facebook). Each participant was also contacted once by telephone. Face-to-face visits were arranged by NP for those who requested.

\section{Participants}

The participants were PHPs employed at PCCs in six selected districts of Sakonnakhon $(N=18)$ with large numbers of childbirths in Sakonnakhon in recent years [31]. There was no specific criteria for selecting the participants in this study. We calculated the sample size [40]. Mean differences and standard deviations (SDs) (based on our pilot study in a province near Sakonnakhon) were: knowledge score $=1.2$ and 1.12, attitude score $=4.0$ and 3.11, and self-efficacy score $=4.0$ and 4.3; $\beta$ was $80 \%$ and $\alpha$ was 0.05 . After some losses, the final number of participants was 33 .

After the four-week period of field practice, we invited by telephone all participants from the KAS-program to take part voluntarily in four focus group discussions (FGDs). Twenty-three PHPs agreed to participate in focus groups as follows: FGD1 $(n=8), \operatorname{FGD} 2(n=6)$, FGD3 $(n=5)$, and FGD4 $(n=4)$. Ten participants could not participate in the FGDs because of, e.g., urgent tasks when the FGDs were held.

\section{Procedure}

We submitted the proposed research study to the Ethics Committee for approval, while the heads of the Health Promotion Department of Sakhonnakhon Provincial Public Health Office and of the District Public Health Offices approved the KAS-program and the data collection. Thereafter we sent, by ordinary post, invitation letters together with socio-demographic characteristics questionnaires (concerning age, gender, marital status, level of education, training experience in mental health field, size of workplace, and working experience in PCCs) and documents about the study to PHPs in PCCs in the six selected districts of Sakonnakhon. One hundred and thirty-four PHPs agreed to participate in the KAS-program and signed a consent form. Later, PHPs who had agreed were selected to participate in the KAS-program using a simple randomization method. The selected PHPs were informed about their participation in the day of theory at the Sakhonnakhon Provincial Public Health Office.

On the day of theory, the authors informed the participants about the aims of the study, their rights as participants in the KAS-program and their option to withdraw from the KAS-program. The participants were asked to three times complete a questionnaire about knowledge, attitude, and self-efficacy for identification and management of perinatal depressive symptoms: (T1) before the first lecture in the day of theory, (T2) after the last lecture in the day of theory, and (T3) immediately after finishing the field practice before the FGDs or on a day close to the last FGD (in any FGD in cases of non-participation). See Fig. 2.

The FGDs were conducted in district public health offices in Sakonnakhon at a time and date the participants preferred. Each FGD, with NP and PCL present, was audio-recorded and lasted approximately $2 \mathrm{~h}$. After this time, no new information emerged. NP, male author with a degree in public health and experience of qualitative research, served as moderator. PCL, female author, nurse/midwife and $\mathrm{PhD}$ with experience of qualitative research, took notes and clarified answers from the participants when needed. The authors had no previous relation to the participants. After each FGD, NP transcribed the recordings verbatim and checked the accuracy of the transcripts. All transcripts were coded without name identification.

\section{Instruments}

A questionnaire was developed for this study by the authors (see Additional file 1). It consisted of three parts related to perinatal depressive symptom identification and management: (1) knowledge of, (2) attitude towards, and (3) self-efficacy for such activities in their profession. Three experts approved the content of the questionnaire (Content Validity Index: $\mathrm{CVI}>0.80$ ). Internal consistency of the questionnaire was tested with 30 PHPs who worked in PCCs nearby Sakonnakhon (the Cronbach's alpha coefficient for the whole questionnaire was 0.96).

The knowledge and attitude parts were based on a questionnaire intended to train Thai PHPs and public health assistants [41]. Adjustments for the purpose of this study were made by the authors. Twelve questions concerned knowledge of perinatal depressive symptom identification and management. Each question could give a score of zero or one if the answer was incorrect or correct, respectively. Thus, the total score of this part could be $0-12$, and a higher score meant more knowledge. Ten questions concerned attitude towards identification and management of perinatal depressive symptoms. Each question had a fourlevel Likert-scale: Strongly agree, agree, disagree, and strongly disagree, and could be scored between one and four. Thus, the total score could be 10-40, and a higher score meant more positive attitude.

The self-efficacy part was based on Thai validated version [42] of the Generalized Self-Efficacy Scale [43]. Adjustments for the purpose of this study were made by the authors. It had ten items, each with four options (not at all true, hardly true, moderately true, and exactly 


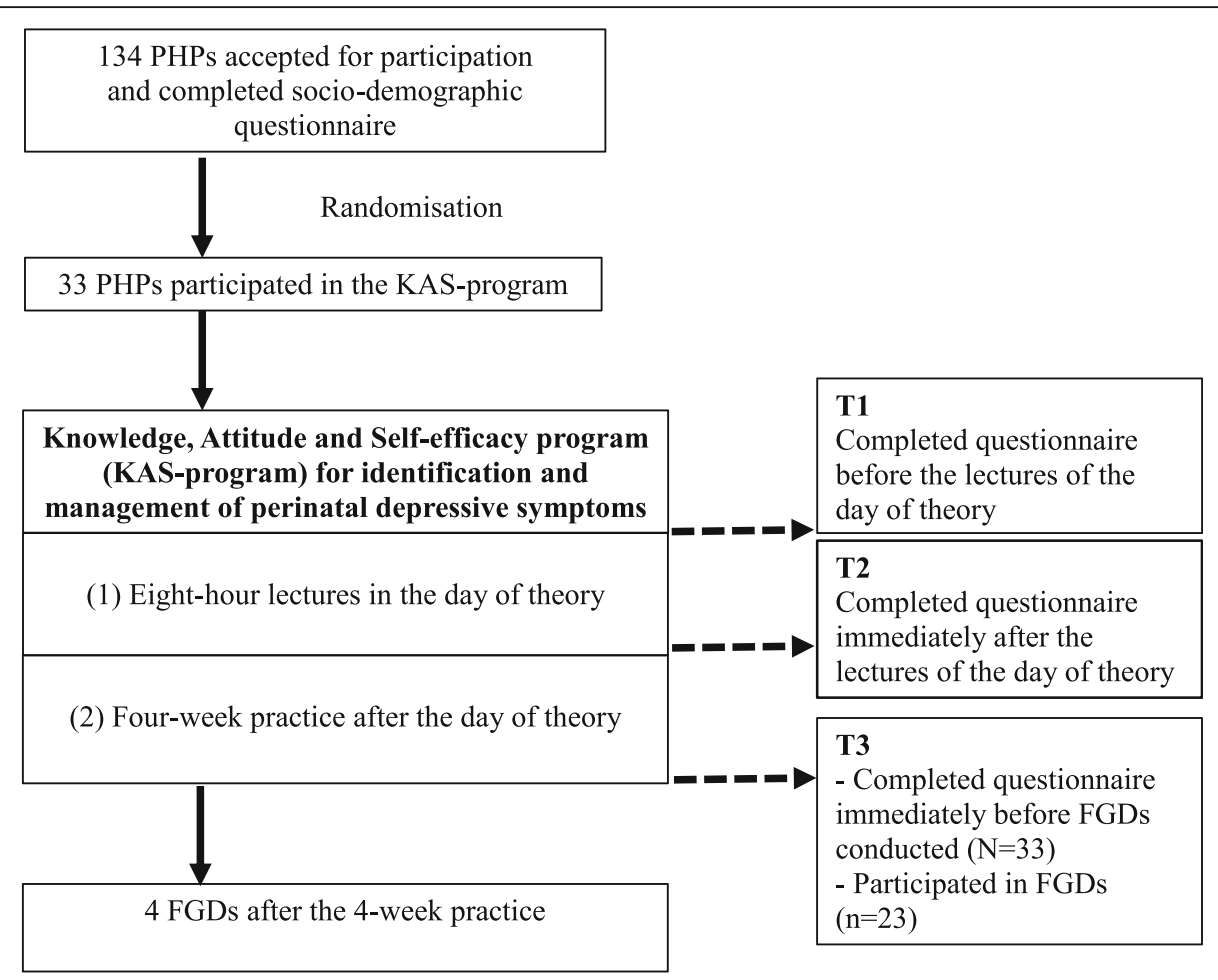

Note: FGD, Focus Group Discussion; PHP, Public Health Professional; KAS-program, Knowledge, Attitude, and Self-efficacy program

Fig. 2 Flow diagram for the quasi-experimental study

true), providing a score $1-4$. Thus, the total score could be $10-40$, and a higher score meant higher self-efficacy.

An interview guide for use in the FGDs was developed for this study by the authors. The interview guide contained eight open-ended questions letting the participants in the FGDs describe and discuss their knowledge of, attitude towards, and self-efficacy for identification and management of perinatal depressive symptoms after participation in the KAS-program. It was tested in the first FGD and adjusted before use in the remaining FGDs. The first FGD was involved in the qualitative analysis. Example questions were: (1) "How has your knowledge changed after you participated in the KASprogram?" and (2) "Please share your experiences from participating in the four-week period of field practice of the KAS-program".

\section{Analyses}

Different statistics were used for analyses of the questionnaire. Descriptive statistics were applied to summarize socio-demographic characteristics of the participants using frequency, percent, mean, $\mathrm{SD}$, and range. Assumptions for paired-sample $\mathrm{T}$ test were satisfied (i.e., continuous variables, independent observations, normal distribution shown by skewness values was between -0.7 and 0.5 , and no outliners defined by kurtosis values were less than 2). Therefore, Chi-square test for trend analysis was used to determine changes of mean scores of the knowledge, attitude and self-efficacy over three time points, and paired-sample $\mathrm{T}$ test was used to compare the mean scores between times. The significance level was set at 0.05 , and $95 \%$ confidence interval was used.

Data from FGDs were analyzed using qualitative content analysis [44]. It focused on meaning units (words or sentences), condensed meaning units, codes, subcategories and categories, where the categories represented the processes during and after implementation of the KAS-program. First, the authors read all transcripts separately. Thereafter, they discussed categories until agreement was reached. The categories were reported to the participants, and the feedback from them did not result in any adjustments. Example quotations were translated from Thai to English and back by the authors who were Thai natives with good knowledge of English. They are shown in the result section with indication of the focus group (FGD1-4). 


\section{Results}

Most participants were female (66.7\%) and single (57.6\%). Two-thirds of them were at most 30 years old, their age ranging from 22 to 54 years. See Table 1.

\section{Quantitative results}

The knowledge scores of perinatal depressive symptom identification and management increased significantly from 8.94 at $\mathrm{T} 1$ (before lectures the day of theory) to 9.45 at $\mathrm{T} 2$ (after lectures the day of theory), and remained the same from T2 to T3 (after 4 weeks of field practice) ( $\mathrm{p}$ for trend $=0.031$ ). The attitude scores toward identification and management of perinatal depressive symptoms improved significantly from 28.94 at T1 to 29.88 at $\mathrm{T} 2$, and from $\mathrm{T} 2$ to 30.42 at $\mathrm{T} 3$ (p for trend $=0.004)$. Self-efficacy scores for perinatal depressive symptom identification and management were unchanged from 26.79 at $\mathrm{T} 1$ to $26.33 \mathrm{~T} 2$, and showed improvement from T2 to 28.73 at T3 $(p=0.043$ for trend). See Table 2.

Table 1 Characteristics of participants in the study

\begin{tabular}{|c|c|}
\hline Characteristics of participants & $N$ (percent) \\
\hline \multicolumn{2}{|l|}{ Gender } \\
\hline Female & $22(66.7)$ \\
\hline Male & $11(33.3)$ \\
\hline \multicolumn{2}{|l|}{ Age (years) } \\
\hline$\leq 30$ & $20(60.6)$ \\
\hline $31-40$ & $8(24.2)$ \\
\hline$>40$ & $5(15.2)$ \\
\hline \multicolumn{2}{|c|}{ Mean $(S D)=32.2(7.60)$, Range $=22-54$} \\
\hline \multicolumn{2}{|l|}{ Marital status } \\
\hline Single & $19(57.6)$ \\
\hline Married & $13(39.4)$ \\
\hline Widowed & $1(3.0)$ \\
\hline \multicolumn{2}{|c|}{ Training experience in mental health field } \\
\hline No & $30(90.9)$ \\
\hline Yes & $3(9.1)$ \\
\hline \multicolumn{2}{|l|}{ Working duration in a PCC } \\
\hline $1-5$ years & $15(45.4)$ \\
\hline $6-10$ years & $12(36.4)$ \\
\hline$>10$ years & $6(18.2)$ \\
\hline \multicolumn{2}{|l|}{ Mean $(S D)=7.1(5.31)$, Range $=1-26$} \\
\hline \multicolumn{2}{|l|}{ Size of current PCC } \\
\hline Small & $4(12.1)$ \\
\hline Medium & $22(66.7)$ \\
\hline Large & $7(21.2)$ \\
\hline
\end{tabular}

Note: PCC Primary care centre; SD Standard Deviation

\section{Qualitative results}

Four categories related to PHPs having participated in the KAS-program emerged: increased understanding and knowledge, being aware and having a positive attitude, having confidence and ability to work, and need of regular training and feedback.

\section{Increased understanding and knowledge}

All FGD participants described that after the KASprogram they had increased their understanding of perinatal depressive symptoms among women. Most participants without previous knowledge of perinatal depression indicated that after participating in the theoretical and practical parts of KAS-program they had gained knowledge. Also, a few participants with mental health education indicated increased knowledge. The participants mentioned that the program was valuable because it made them pay more attention to the mental health of women during pregnancy and after childbirth. It was important to identify pregnant women for antenatal depressive symptoms and manage postpartum depressive symptoms by giving them help and support. The participants described that pregnant women coming to ANC clinics used to have a pink book of mother-and-child health called "Samud Anamai Manda", and they received a mental health screening called $2 \mathrm{Q}$ with only two questions at their first ANC visit. Usually, no mental health problem or depression was found among pregnant women by use of $2 \mathrm{Q}$. If a mental health problem of a pregnant woman was found, she was referred to hospital. The participants also found that compared with $2 \mathrm{Q}$, the screening tool from the KAS-program was very useful for evaluation of depressive symptoms of pregnant and postpartum women.

After participating in this program, I have increased my knowledge of mental health during pregnancy and after childbirth. ... I did not have this knowledge before. I can use it in my work. (FGD1).

I know more about screening of perinatal depressive symptoms, particularly in pregnant women. Before my work was about screening for depression among teenagers, from 15 years, without focus on pregnant women. I think I have got a new method that is helpful for screening work after the program. (FGD2).

The program is good for us (PHPs). We have increased our understanding of mental health among women. I have received a manual for prevention of perinatal depressive symptoms to use. 
Table 2 The differences of scores of knowledge of, attitude towards and self-efficacy for perinatal depressive symptom prevention between times

\begin{tabular}{|c|c|c|c|c|c|c|c|c|}
\hline \multirow[t]{2}{*}{ Items } & \multicolumn{4}{|l|}{ Mean \pm SD } & \multirow{2}{*}{$\begin{array}{l}\text { Changed } \mathrm{T} 1 \text { to } \mathrm{T} 2 \\
\text { mean }(95 \% \mathrm{Cl})\end{array}$} & \multirow[b]{2}{*}{$p$-value } & \multirow{2}{*}{$\begin{array}{l}\text { Changed } \mathrm{T} 2 \text { to } \mathrm{T} 3 \\
\text { mean }(95 \% \mathrm{Cl})\end{array}$} & \multirow[b]{2}{*}{$p$-value } \\
\hline & $\mathrm{T} 1$ & $\mathrm{~T} 2$ & T3 & $p$ for trend $t$ & & & & \\
\hline Knowledge & $8.94 \pm 0.75$ & $9.45 \pm 0.75$ & $9.42 \pm 1.12$ & $.031^{*}$ & $0.52(0.22,0.81)$ & $.001^{*}$ & $0.03(-0.41,0.35)$ & .872 \\
\hline Attitude & $28.94 \pm 3.17$ & $29.88 \pm 4.21$ & $30.42 \pm 2.54$ & $.004^{*}$ & $0.94(0.09-1.78)$ & $.031^{*}$ & $1.52(0.39-2.64)$ & $0.010^{*}$ \\
\hline Self-efficacy & $26.79 \pm 3.87$ & $26.33 \pm 4.12$ & $28.73 \pm 2.95$ & $.043^{*}$ & $-0.45(-1.45,0.55)$ & .363 & $2.39(1.23,3.56)$ & $<.001^{*}$ \\
\hline
\end{tabular}

Note: SD Standard Deviation; T1, before lectures in the theoretical day; T2, after lectures in the theoretical day; T3, before the FGDs conducted; CI Confidence interval; $\dagger$, obtained by Chi-square trend analysis

* statistically significant at 0.05 level

I know that women can have depressive symptoms from pregnancy to 1 year after childbirth. (FGD4).

\section{Being aware and having a positive attitude}

All participants described that after the KAS-program they had increased their awareness and changed their attitude towards perinatal depression. They mentioned that they had a more positive attitude than before to work with this problem. They described that when pregnant women come to ANC clinics they focused on the women's physical health and carried out pregnancy examinations. Therefore, they could not see if pregnant women had depressive symptoms. When their attitude had been changed they considered working with the women's mental health by talking, listening and giving advice.

After the program, I have opened my mind to have a new perspective on women's depressive symptoms during pregnancy and after delivery. I have a positive attitude to work that supports the women. (FGD1).

I think we realize this problem (perinatal depressive symptoms) after the program. Before, I believed that the symptom could disappear by itself after delivery. As PHPs we should consider and detect this problem and promote mental health. (FGD2).

\section{Having confidence and ability to work}

All participants indicated that they had more selfconfidence after participating in the KAS-program. They believed that they could work with identifying depressive symptoms by using the manual they had received from the program. They mentioned that their work was disease prevention. Therefore, they should cooperate with nurses/midwifes at PCCs and in this way work with perinatal depression as a team and close to people in their community, particularly women during pregnancy and after childbirth. They described that according to the Ministry of Public Health in Thailand, the important work of primary care should be "located close to where people live" (Klaibarn, Klaijai). Therefore, they worked together with nurses/midwives at PCCs to approach women closely concerning mental health promotion in their community.

Our work is prevention of diseases in the community. We know everybody and they trust us. When we visit villages in the community, we could screen depressive symptoms among pregnant women to prevent these symptoms after delivery. (FGD1).

I have more confidence after participating in the program. I believe that I could work with prevention of perinatal depressive symptoms. I will work together with nurses/midwifes to screen women during pregnancy and after delivery. (FGD3).

\section{Need of regular training and feedback}

In the KAS-program, the participants received knowledge for identification and management of perinatal depressive symptoms based on theory and also on practice through screening and its evaluation. They mentioned that it had been very useful to receive coaching during the fieldwork of their practice. However, they would have appreciated getting more such coaching, discussion and feedback. Regular training for identification and management of perinatal depressive symptoms should be provided to PHPs to update their knowledge and increase their self-confidence. The participants also mentioned that nurses/midwives should participate in this training program.

I think it will help us if we would have more time for coaching while we practice screening in the fieldwork. (FGD2).

I think we are aware of perinatal depressive symptoms and have more knowledge than before but I think PHPs and nurses/midwives still need regular training in this area so that we can work with women's mental health promotion. (FGD4). 


\section{Discussion}

This study revealed that the PHPs had generally no or little knowledge about identifying and managing perinatal depressive symptoms before participating in the KAS-program. This is in accord with several studies showing that the knowledge of Thai HCPs for a specific task is often insufficient [23, 24], particularly the knowledge for management of depressive symptoms in communities [21]. In this study, knowledge scores for identification and management of perinatal depressive symptoms among PHPs increased immediately after the participants had finished their participation in the interactive lectures in the day of theory. Thereafter, the scores remained on the same level till after the 4 weeks of field practice. Further, at the end of the KAS-program the PHPs described their understanding of how to identify and manage perinatal depressive symptoms and to use the EPDS for women. Perhaps the guidelines and the questionnaire presented in the lectures of the day of theory filled a knowledge gap of the PHPs, while field practice during 4 weeks maintained the PHPs' knowledge for identification and management of perinatal depressive symptoms. A specific training program can increase the knowledge of HCPs [9], while a knowledge gap of HCPs for identification of depression is filled if HCPs are advocated for depression screening in women [17]. Having enough knowledge can also make HCPs' able to improve mental health services in a PCC, particularly HCPs may improve psychosocial management among women during the perinatal period [6, 16, 19]. Nowadays, public primary healthcare services in Thailand have the same structure and organization, e.g., ANC clinics [22]. The KAS-program is of interest for dissemination also to other HCPs, like nurses/midwives [6]. Therefore, HCPs in PCCs can have sufficient knowledge to identify and manage perinatal depressive symptoms in the future [21, 23].

When HCPs perform screening routinely for perinatal depressive symptoms and feel a screening tool is useful, they may have a positive attitude to work with identification of such symptoms [17]. The KAS-program demonstrated gradual changes of the attitude scores toward identifying and managing perinatal depressive symptoms, from before lectures in the day of theory longitudinally till after 4 weeks of practice. The participants also described having more positive attitude and awareness to work with perinatal depressive symptoms. Their attitude might be changed by (1) shared experience and lectures provided in the day of theory based on the four components of the Bandura's self-efficacy theory [30], and (2) their supervised practice during 4 weeks. It is necessary for HCPs to manage perinatal depressive symptoms [6]. However, they need a training program within 5 years, otherwise their attitudes may not improve [9].
The attitude among HCPs in Thailand is often negative when they take care of specific patients [24, 25]. The KAS-program seemed to improve the PHPs' attitude towards identification and management of perinatal depressive symptoms and made them recognize the importance of this task. A training program focusing on attitudes among HCPs, like the KAS-program, should be managed and implemented on a policy level [26].

Our results demonstrated improvement not only of the participants' self-efficacy scores for identification and management of perinatal depressive symptoms, but also of their ability to work with perinatal depressive symptoms after finishing the KAS-program. Four main components of Bandura's self-efficacy theory (i.e., performance accomplishment, vicarious experience, verbal persuasion, and physiological states) contribute to selfefficacy and they should be included in training programs [30]. Performance accomplishment and vicarious experience are important components of increasing HCPs' self-efficacy [28], while verbal persuasion and physiological states are key points that make HCPs have self-efficacy to provide mental health services [19]. In this study, the four main components were considered and used both in the day of theory and during the 4 weeks of field practice. The participants described that they had confidence and ability to identify and manage perinatal depressive symptoms because during 4 weeks, they practiced with two or more women during the perinatal period. They also expressed that they would get more self-confidence if they had a regular training and the opportunity of talking with other HCPs, e.g., nurses/ midwifes. Moreover, there was an increasing trend of the participants' self-efficacy scores from before the lecture of the day of theory till after 4 weeks of practice. Increased practice in PCCs can promote high self-efficacy among HCPs, while regular training may enhance the ability to perform mental health tasks [28]. In Thailand, a follow-up session can improve outcomes of a training program [29], and regular training along with supervision is a challenge in PCCs in Thailand in order to enhance competency of HCPs to manage perinatal depressive symptoms [23, 25]. Therefore, the KASprogram in this study is important for PHPs at primary care settings to improve their knowledge, attitudes and self-efficacy. This program should be useful also for other HCPs such as nurses/midwives at primary care settings and at hospitals. Future research should evaluate the KAS-program using smartphone applications that were found to be useful in treatment of perinatal depression $[45,46]$.

\section{Strengths and limitations}

The study relied on Bandura's self-efficacy theory. Effectiveness of a training program could be well demonstrated 
by using a quasi-experiment with mixed methods data collection approach [47]. Sample calculation and data analysis were carried out in order to evaluate quantitatively the knowledge, attitude and self-efficacy for identification and management of perinatal depressive symptoms. Although a number of studies have shown that training can improve the capacity among nurses and physicians to identify and manage perinatal depressive symptoms, we have not been able to find similar studies for PHPs in PCCs. Therefore, the contribution of this study to existing knowledge is unique.

A limitation was that the KAS-program was followed up on a four-week basis. Increased time for follow-up might show a greater change of knowledge, attitude and self-efficacy. For further study of the effectiveness of the program there is need of a control group.

\section{Conclusions}

The KAS-program, based on four main components of Bandura's self-efficacy theory, had both a day of theory and a four-week period of practice. The program increased the knowledge, attitude, and self-efficacy scores among PHPs in PCCs for identification and management of perinatal depressive symptoms. The participating PHPs had increased knowledge and awareness, positive attitude, and increased confidence and ability to work. However, they wished to have regular training and feedback after finishing the KAS-program. It is recommended to implement the KAS-program nationally also to other HCPs such as nurses/midwives.

\section{Supplementary Information}

The online version contains supplementary material available at https://doi. org/10.1186/s12889-020-10086-9.

\section{Additional file 1.}

\section{Abbreviations}

ANC: Antenatal care; CVI: Content validity index; EPDS: Edinburgh postnatal depression scale; FGD: Focus group discussion; HCP: Healthcare professional; KAS-program: Knowledge, attitude and self-efficacy program; PCC: Primary care centre; PHP: Public health professional; SD: Standard deviation; $\mathrm{T1}$ : Before the first lecture in the day of theory; T2: After the last lecture in the day of theory; T3: Immediately after finishing the field practice

\section{Acknowledgements}

The authors thank the public health professionals who participated in this study. We also thank the staff and directors at Sakonnakhon Public Health Provincial and District Offices for facilitating data collection.

\section{Authors' contributions}

NP conceived of the study, collected data, performed the quantitative and qualitative analyses, interpreted data and wrote the manuscript. PCL designed the study, collected data, analysed qualitative data, interpreted data and helped to write the manuscript. All authors read and approved the final manuscript.

\section{Funding}

This study was supported by the Department of Public Health and Caring Sciences, Uppsala University, Sweden, and Kasetsart University
Chalermphrakiat Sakonnakhon Province Campus, Thailand. The funding sources had no role in the collection or analysis of data. Open Access funding provided by Uppsala University.

\section{Availability of data and materials}

The datasets used and/or analysed during the current study are available from the corresponding author on reasonable request.

\section{Ethics approval and consent to participate}

The ethical considerations were approved by the Ethics Committee in Thailand (SWDCPH2017-003). Permission was received also from the Heads of the Sakonnakhon Provincial Public Health Office and of the District Public Health Offices. All participants received information, both oral and written, before signing a consent form. The information emphasised that their participation in the study was voluntary and that the participants were fully entitled to withdraw from participation at any time. None of the authors was involved in any participants' tasks. Confidentiality was maintained and privacy was assured.

\section{Consent for publication}

Not applicable.

\section{Competing interests}

The authors declare that they have no competing interests.

Received: 2 June 2020 Accepted: 17 December 2020

Published online: 30 December 2020

\section{References}

1. Phoosuwan N, Eriksson L, Lundberg PC. Antenatal depressive symptoms during late pregnancy among women in a north-eastern province of Thailand: prevalence and associated factors. Asian J Psychiatr. 2018:36:102-7.

2. Roomruangwong C, Epperson N. Perinatal depression in Asian women: prevalence, associated factors, and cultural aspects. Asian Biomed. 2011;5: 179-93.

3. Whiteford HA, Degenhardt L, Rehm J, Baxter AJ, Ferrari AJ, Erskine HE, et al. Global burden of disease attributable to mental and substance use disorders: findings from the global burden of disease study. Lancet. 2013; 382(9904):1575-86.

4. Evans MG, Phillippi S, Gee RE. Examining the screening practices of physicians for postpartum depression: implications for improving health outcomes. Womens Health Issues. 2015;25(6):703-10.

5. Phoosuwan N, Manwong M, Eriksson L, Lundberg PC. Perinatal depressive symptoms among Thai women: a hospital-based longitudinal study. Nurs Health Sci 2019:1-9. https://doi.org/https://doi.org/10.1111/nhs.12669.

6. Dennis $\mathrm{CL}$, Dowswell T. Psychosocial and psychological interventions for preventing postpartum depression. Cochrane Database Syst Rev. 2013;2. https://doi.org/10.1002/14651858.CD001134.pub3.

7. O'Connor E, Senger CA, Henninger ML, Coppola E, Gaynes BN. Interventions to prevent perinatal depression: evidence report and systematic review for the US preventive services task force. JAMA. 2019;321(6):588-601.

8. Stuart-Parrigon K, Stuart S. Perinatal depression: an update and overview. Curr Psychiatry Rep. 2014;16(9):468.

9. Greacen T, Jouet E, Ryan P, Cserhati Z, Grebenc V, Griffiths C, et al. Developing European guidelines for training care professionals in mental health promotion. BMP Public Health. 2012;12:1114.

10. Gale J, Marshall-Lucette S. Community mental health nurses' perspectives of recovery-oriented practice. J Psychiatr Ment Health Nurs. 2012;19:348-53.

11. Cleary A, Dowling N. Knowledge and attitudes of mental health professionals in Ireland to the concept of recovery in mental health: a questionnaire survey. J Psychiatr Ment Health Nurs. 2009;16:539-45.

12. Hungerford C, Dowling M, Doyle K. Recovery outcome measures: is there a place for culture, attitudes, and faith. Perspect Psychiatr Care. 2015;15:171-9.

13. Peebles SA, Mabe PA, Fenley G, Buckley PF, Bruce TO, Narasimhan M, et al. Immersing practitioners in the recovery model: an educational program evaluation. Community Ment Health J. 2009;45:239-45.

14. United Nations: Health - United Nations Sustainable Development. (2017) http://www.un.org/sustainabledevelopment/health/. Accessed 25 Dec 2018.

15. Phoosuwan N, Manasatchakun P, Eriksson L, Lundberg PC. Life situation and support during pregnancy among Thai expectant mothers with depressive 
symptoms and their partners: a qualitative study. BMC Pregnancy Childbirth 2020;20:207. https://doi.org/https://doi.org/10.1186/s12884-020-02914-y.

16. Niemi M, Kiel S, Allebeck P, Hoan LT. Community-based intervention for depression manangement at the primary care level in Ha Nam Province, Vietnam: a cluster-randomised controlled trial. Tropical Med Int Health. 2016;21(5):654-61.

17. Buist A, Condon J, Brooks J, Speelman C, Milgrom J, Hayes B, et al. Acceptability of routine screening for perinatal depression. J Affect Disord. 2006;93:233-7.

18. Cox JL, Holden JM, Sagovsky R. Detection of postnatal depression. Development of the 10-item Edinburgh postnatal depression scale. Br J Psychiatry. 1987;150:782-6.

19. Saraceno B, van Ommeren M, Batniji R, Cohen A, Gureje O, Mahoney J, et al. Barriers to improvement of mental health services in low-income and middle-income countries. Lancet. 2007:370:1164-74.

20. Patel V, Weiss HA, Chowdhary N, Naik S, Pednekar S, Chatterjee S, et al. Effectiveness of an intervention led by lay health councellors for depressive and anxiety disorders in primary care in Goa, India (MANAS): a cluster randomized controlled trial. Lancet. 2010;376:2086-95.

21. Kongsuk T, Supanya S, Kenbubpha K, Phimtra S, Sukhawaha S, Leejongpermpoon J. Services for depression and suicide in Thailand. WHO South East Asia J Public Health. 2017;6(1):34-8.

22. Hanucharurnkul S. Nurses in primary care and the nurse practitioner role in Thailand. Contemp Nurse. 2007;26(1):83-93.

23. Rugsanor I, Chaiviboontham S, Pokpalagon P. Knowledge, attitude, and selfefficacy in end-of-life care of senior military student nurses. J Royal Thai Arm Nurs. 2018;19:242-50.

24. Srisuwan N, Matchim Y, Nilmanat K. Nurses' competency in communication with patients at the end of life and their families and related factors. Songklanagarind J Nurs. 2014;34(3):109-24.

25. Lotrakul M, Saipanish R. Psychiatric services in primary care settings: a survey of general practitioners in Thailand. BMC Fam Pract 2006;7(1):48. https://doi. org/https://doi.org/10.1186/1471-2296-7-48.

26. Magor-Blatch LE, Rugendyke AR. Going smoke-free: attitudes of mental health professionals to policy change. J Psychiatr Ment Health Nurs. 2016; 23(5):290-302

27. Shore TH, Tashchian A, Adams JS. Development and validation of a scale measuring attitudes toward smoking. J Soc Psychol. 2000;140:615-23.

28. Zamani-Alavijeh F, Araban M, Harandy TF, Bastami F, Almasian M. Sources of health care providers' self-efficacy to deliver health education: a qualitative study. BMC Med Edu. 2019;19:16.

29. Lundberg PC, Thrakul S. Self-care management of Thai Buddhists and Muslims with type 2 diabetes after an empowerment education program. Nurs Health Sci. 2018:20:402-8.

30. Bandura A. The explanatory and predictive scope of self-efficacy theory. J Soc Clin Psychol. 1986;4:359-73.

31. National Statistics Office: Births and deaths by sex: 2006-2015. (2016) http:// sakonnk.old.nso.go.th/nso/project/search_option/index.jsp?province_id=75 \&depcode $=01$ \&gcode $=01 \&$ ccode $=01 \&$ subcode $=01$. Accessed 10 May 2018 .

32. Creswell JW, Clark VP. Designing and conducting mixed methods research. London: SAGE Publications Ltd; 2007.

33. White $H$, Sabarwal S. Quasi-experimental design and methods: methodological brief-impact evaluation no.8. Unicef Office of Research: Florence; 2014.

34. World Health Organisation. Thinking Healthy: A manual for psychosocial management of perinatal depression (WHO generic field-trial version 1.0). Geneva: WHO; 2015

35. Phoosuwan N, Eriksson L, Lundberg PC. Statistical analyses of the Thai version of the Edinburgh postnatal depression scale among Thai women during the antenatal period in North-Eastern Thailand. In: The $5^{\text {th }}$ PSU-USM international conference on arts and sciences 2017, Phuket. Thailand: Prince of Songkla University Press; 2017. p. 685-700.

36. Pitanupong J, Liabsuetrakul T, Vittayanont A. Validation of the Thai Edinburgh postnatal depression scale for screening postpartum depression. Psychiatry Res. 2007;149:253-9.

37. Nilchaikovit T, Sukying C, Silpakit C. Reliability and validity of the Thai version of the general health questionnaire. J Psychiatric Assoc Thailand. 1996:41:2-17.

38. Wongpakaran T, Wongpakaran N. A comparison of reliability and construct validity between the original and revised versions of the Rosenberg selfesteem scale. Psychiatry Investig. 2012;91:54-8.
39. Antonovsky A. Unraveling the mystery of health: how people manage stress and stay well. San Francisco: Jossey-Bass; 1987

40. Chow S, Shao J, Wang H. Sample size calculation in clinical research. London: Chapman \& Hall/CRC; 2003.

41. Ministry of Public Health. Training manual on depression patients health services among nurses, public health professionals and public health assistants. Nonthaburi, Thailand: Department of Mental Health Press; 2015.

42. Sukmak V, Sirisoonthon A, Meena P. Validity of the general perceived selfefficacy scale. J Psychiatric Assoc Thailand. 2001;47(1):31-17.

43. Schwarzer R, Jerusalem M. Generalized Self-Efficacy Scale. In: Weinman J, Wright S, Johnston M, editors. Measures in health psychology: A user's portfolio. Causal and control beliefs. Windsor, UK: Nfer-Nelson; 1995. p. 35-7.

44. Graneheim U, Lundman B. Qualitative content analysis in nursing research: concepts, procedures and measures to achieve trustworthiness. Nurse Educ Today. 2004;24:105-12.

45. Fealy S, Chan S, Wynne O, Dowse E, Ebert L, Ho R, Zhang MW, et al. The support for new mums project: a protocol for a pilot randomized controlled trial designed to test a postnatal psychoeducation smartphone application. J Adv Nurs. 2019;75(6):1347-59. https://doi.org/10.1111/jan.13971.

46. Zhang MW, Ho RC, Loh A, Wing T, Wynne O, Chan SW, et al. Current status of postnatal depression smartphone applications available on application stores: an information quality analysis. BMJ Open. 2017;7(11):e015655. https://doi.org/10.1136/bmjopen-2016-015655.

47. Pradhan NA, Mughis W, Ali TS, Naseem M, Karmaliani R. School-based interventions to promote personal and environmental hygiene practices among children in Pakistan: protocol for a mixed methods study. BMC Public Health. 2020;20:481.

\section{Publisher's Note}

Springer Nature remains neutral with regard to jurisdictional claims in published maps and institutional affiliations.

\section{Ready to submit your research? Choose BMC and benefit from:}

- fast, convenient online submission

- thorough peer review by experienced researchers in your field

- rapid publication on acceptance

- support for research data, including large and complex data types

- gold Open Access which fosters wider collaboration and increased citations

- maximum visibility for your research: over $100 \mathrm{M}$ website views per year

At BMC, research is always in progress.

Learn more biomedcentral.com/submissions 